\title{
Yoga: a tool for amelioration of obesity
}

\author{
Navneet Kaur ${ }^{\mathrm{a}, \mathrm{d}}$, Neeru Malik ${ }^{\mathrm{b} *}$, Pooja Sharma ${ }^{\mathrm{c}}$, Akshay Anand $^{\mathrm{d}}$

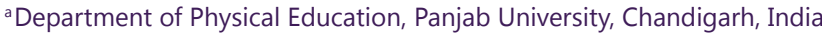 \\ ${ }^{\mathrm{b}}$ Dev Samaj College of Education, Chandigarh, India \\ 'Residence of Panjab University Campus, Chandigarh, India \\ d Department of Neurology, Neuroscience Research Lab, Postgraduate Institute of Medical Education and Research, Chandigarh, India
}

\section{KEY WORDS}

Obesity

Lifestyle

Diabetic Yoga Protocol

\section{*Corresponding Author:}

Neeru Malik, PhD

DSCE, Sec-36, Chandigarh

Contact no: +91-9781133666

E-mail: drneerumalikhry@gmail.com

\begin{abstract}
In this study the case of overweight/obese participant is presented. The participant is a resident of Panjab University, Chandigarh, India. She voluntarily enrolled herself in the Yoga camp which was conducted at Gymnasium Hall, Panjab University, Chandigarh. The patient performed the Diabetic Yoga protocol for one month. The weight of the patient before joining the Yoga camp was $96 \mathrm{~kg}$ and the height was $170 \mathrm{~cm}$. During the conversation, the patient revealed that during the practice of one month Diabetic Yoga protocol she lost $6 \mathrm{~kg}$ of her weight. This case report is an attempt to provide Yoga as safe, economical and simple technique for weight reduction. doi: $10.38205 /$ imcr.010129
\end{abstract}

\section{Introduction}

The problem of Obesity is increasing globally and has emerged as a precursor of major health problems. Obese individuals are at a greater risk of developing comorbidities like Diabetes Mellitus, Cardiovascular Diseases, respiratory and psychological Problems etc. (1). According to World Health Organization, obesity is an exaggerated buliding up of fat which presents risk to health (2). Body Mass Index (BMI) is used to measure body fat by using the measurements of height and weight. An individual is found to be overweight and obese if he/she had a BMI of $\geq 25 \mathrm{~kg} / \mathrm{m}^{2}$ and $\geq 30 \mathrm{~kg} / \mathrm{m}^{2}$ respectively (3). According to the National Family Health Survey (NFHS) it was found that the prevalence of overweight and obesity was more than 3 times higher among urban population in comparison with rural population (4). Moreover, overweight and obesity are more among women population as compared to males. The maximum proportion of overweight and obese female population was found in Punjab (30\%) followed by Kerala (28\%) and Delhi (26\%) (4). We argue that India can achieve healthy weight by convenient and home based Yoga, meditation and exercise programs (5). Life modification such as Yoga has been used as one of the effective ways as management of weight (6). Yoga is a mind body practice which focuses upon overall well being of an individual viz. physical, mental, emotional and spiritual (7). Various studies have shown the efficacy of Yoga in reduction of weight (8) (6).

\section{Case presentation}

The participant is a resident of Panjab University, Chandigarh, India. She was enrolled in the Yoga camp which was conducted at Gymnasium Hall, Panjab University, Chandigarh by a Yoga instructor. As per the conversation with the participant she revealed that she was struggling with consistent weight gain and wanted to manage her weight without taking any medications. She further added that she started gaining her weight after her pregnancy. During her pregnancy she was diagnosed with thyroid. She also took medication for the same. At present, she had no associated illness with obesity and didn't take any kind of medications. Moreover, the participant had no family history of obesity and its associated cormobidities. The participant was trained for the Diabetic Yoga Protocol for one month and after that she continued to perform the same at home for 2 months. The weight of the patient, before joining the Yoga camp, was $96 \mathrm{~kg}$ with a height of $170 \mathrm{~cm}$. Her BMI was $33.2 \mathrm{~kg} / \mathrm{m}^{2}$. This falls in the category of Obese I.

The three month Yoga camp was conducted in Panjab University, Chandigarh. The detailed Diabetic Yoga protocol was shown in our previously published paper (18). The height and weight measurement were taken pre and post Yoga practices. The weight was measured by electronic weighing machine and height was measured by using Stadiometer. Furthermore, written informed consent was taken from the participant. In addition, sociodemographic characterstics of the participant are shown in Table 1.

According to World Health Organization, obesity is a disproportionate or exaggerated accumulation of fat which further results into several consequences to the well being of the individuals. Body Mass Index ((BMI $\left.-\mathrm{kg} / \mathrm{m}^{2}\right)$ was used for assessment of overweight and obesity in the individuals by using the formula weight in the Kilograms divided by the square of the height in meters. Furthermore, the recommended values for the 
Table 1: Socio demographic characteristics of the study participant

\begin{tabular}{|l|l|}
\hline Sociodemographic Characteristics & Values \\
\hline Age (Years) & 31 Year \\
\hline Previous Yoga Experience & No \\
\hline Marital Status & Married \\
\hline Education Level & Senior Secondary School \\
\hline Occupation & Home maker \\
\hline
\end{tabular}

Table 2: Characteristics of baseline and after one month DYP and home based values of BMI

\begin{tabular}{|l|l|l|l|}
\hline Variable & Baseline & $\begin{array}{l}\text { One month DYP } \\
\text { with Instructor }\end{array}$ & $\begin{array}{l}\text { Two month Home } \\
\text { Based DYP }\end{array}$ \\
\hline BMI & $33.2 \mathrm{~kg} / \mathrm{m}^{2}$ & $31.1 \mathrm{~kg} / \mathrm{m}^{2}$ & $29.4 \mathrm{~kg} / \mathrm{m}^{2}$ \\
\hline Weight & $96 \mathrm{~kg}$ & $90 \mathrm{~kg}$ & $85 \mathrm{~kg}$ \\
\hline Height & 170 & 170 & 170 \\
\hline $\begin{array}{l}\text { Category (According } \\
\text { to WHO guidelines) }\end{array}$ & $\begin{array}{l}\text { Obese Class - I } \\
(30.00-34.99)\end{array}$ & $\begin{array}{l}\text { Obese Class - I } \\
(30.00-34.99)\end{array}$ & $\begin{array}{l}\text { Overweight } \\
(25.00-29.99)\end{array}$ \\
\hline
\end{tabular}

assessment of overweight and obesity in the individuals were $\mathrm{BMI} \geq 25$ (overweight) and BMI $\geq 30$ (Obesity) respectively (9).

The one month diabetic Yoga Protocol training with instructor and two month home follow up resulted in a significant reduction of weight. The participant experienced reduction weight from the $96 \mathrm{~kg}$ to $85 \mathrm{~kg}$. This results in the reduction of BMI values from $33.2 \mathrm{~kg} / \mathrm{m}^{2}$ (obese I) to $29.3 \mathrm{~kg} / \mathrm{m}^{2}$ (overweight) are shown in Table 2 .

\section{Discussion}

Obesity is a metabolic disorder (10) and the problem of obesity is widely prevalent. However, obesity is also considered as modifiable risk factor $(6,11)$ and Integrative approaches are used popularly all around the world for its management. Yoga is also one of them. Due to modern inactive lifestyle, the risk of obesity has been increasing among the masses (12). By performing the routine physical activity, one can manage and prevent obesity (13). Yoga might be considered as a simple and convenient way for weight management (14). In this case study, the participant performed regular Yoga practice adherent to the training regime which further helped her in weight loss. Furthermore, she was also able to perform all asanas (postures) with enthusiasm resulting in energy consumption and prevent increase in body weight. Additionally, the participant also undertook some dietary changes which included light food at night and excluded fried, sweet and rice from the diet. Besides the physical benefits, Yoga practice is also helpful in giving mental relaxation thus modulating leptin and HPA axis (15)(16)(17).

\section{Conclusion}

Yoga intervention is considered to be an adjuvant therapy in treatment and prevention of weight gain in obese and overweight individuals. However, the results also depend on various factors like age, adherence, frequency and adaptation to the training regime. The DYP protocol which was specifically designed for Prediabetics and Diabetics may be useful for obese and overweight individuals. With reduction in weight, Yoga can provide risk management of Diabetes.

\section{Acknowledgements}

The authors acknowledge Ms. Sarika Dhiman for her valuable inputs. The authors would like to thank the study participant for their involvement in the trial.

\section{Author contributions}

NK: Writing, Data Collection, Analysis and Interpretation of Data.

NM: Co-Conceptualization and Design of the study.

PS: Participant

AA: Conceptualization and Editing of the manuscript.

\section{Informed consent}

Yes. Study was carried out at the center from where report has been communicated.

\section{Conflict of interest}

The authors declares no conflict of interest.

\section{Source of funding}

This study has been supported by University Grants Commission (UGC) via Letter No. 15-9(June 2014)/2014(NET).

Received Date: 15-01-20; Revised Date: 11-02-20;

Accepted Date: $12-02-20$ 


\section{References}

1. Fruh SM. Obesity: Risk factors, complications, and strategies for sustain able long-term weight management. Journal of the American Association of Nurse Practitioners. 2017 Oct;29(S1):S3-14.

2. World Health Organization (WHO). (2016a). 10 Facts on obesity. Retrieved from https://www.who.int/features/factfiles/obesity/facts/en/

3. World Health Organization (WHO). (2016b). Obesity. Retrieved from https://www.who.int/topics/obesity/en/

4. http://www.nfhsindia.org/nfhs3.html. Accessed on 6 March, 2012.

5. Kalra S, Unnikrishnan AG. Obesity in India: The weight of the nation. Journal of Medical Nutrition and Nutraceuticals. 2012 Jan 1;1(1):37.

6. Lauche R, Langhorst J, Lee MS, Dobos G, Cramer H. A systematic review and meta-analysis on the effects of Yoga on weight-related outcomes. Preventive medicine. 2016 Jun 1;87:213-32.

7. Manchanda SC, Madan K. Yoga and meditation in cardiovascular disease Clinical Research in Cardiology. 2014 Sep 1;103(9):675-80.

8. Sarvottam K, Yadav RK. Obesity-related inflammation \& cardiovascular disease: Efficacy of a Yoga-based lifestyle intervention. The Indian journal of medical research. 2014 Jun;139(6):822.

9. Chukhraiev N, Zukow W, Chukhraieva E, Unichenko A. Integrative approach to reduction of excess weight. Journal of Physical Education and Sport. 2017 Jun 1;17(2):563.

10. Hotamisligil GS. Inflammation and metabolic disorders. Nature. 2006 Dec 13;444(7121):860
11. World Health Organization. Global status report on noncommunicable diseases 2014. Geneva: WHO Press; 2014.

12. Cecchini M, Sassi F, Lauer JA, Lee YY, Guajardo-Barron V, Chisholm D. Tackling of unhealthy diets, physical inactivity, and obesity: health effects and cost-effectiveness. Lancet. 2010;376(9754):1775-84.

13. National Health and Medical Research Council. Clinical practice guidelines for the management of overweight and obesity in adults, adolescents and children in Australia. Melbourne: National Health and Medical Research Council; 2013

14. Rioux JG, Ritenbaugh C. Narrative review of Yoga intervention clinical trials including weightrelated outcomes. AlternTher Health Med. 2013;19(3):32-46

15. Arora S, Bhattacharjee J. Modulation of immune responses in stress by Yoga. International journal of yoga. 2008 Jul;1(2):45.

16. Riley KE, Park CL. How does yoga reduce stress? A systematic review of mechanisms of change and guide to future inquiry. Health Psychology Review. 2015 Aug 7;9(3):379-96.

17. Thangasami SR, Chandani AL, Thangasami S. Emphasis of Yoga in the Management of Diabetes. J Diabetes Metab. 2015 Oct 1;6(613):2.

18. Singh AK, Kaur N, Kaushal S, Tyagi R, Mathur D, Sivapuram MS, Metri K, Bammidi S, Podder V, Modgil S, Khosla R. Partitioning of radiological, stress and biochemical changes in pre-diabetic women subjected to Diabetic Yoga Protocol. Diabetes \& Metabolic Syndrome: Clinical Research \& Reviews. 2019 Jul 1;13(4):2705-13. 